\title{
Comparison of PAP Smear and Colposcopy in Detection of Premalignant Lesions of Cervix
}

\author{
${ }^{1}$ Bahar Kohli, ${ }^{2}$ Shashi Bala Arya, ${ }^{3}$ Jai Kishan Goel, ${ }^{4}$ Mridu Sinha, ${ }^{5}$ Jayanti Kar, ${ }^{6}$ Isha Tapasvi
}

\author{
ABSTRACT \\ Objective: Comparison of papanicolaou (PAP) smear and \\ colposcopy in detection of premalignant lesions of cervix.
}

Materials and methods: A prospective clinical study was conducted in a tertiary care referral institute in 100 symptomatic, sexually active women of 20 to 60 years. All women were subjected to PAP smear, colposcopy and cervical biopsy to confirm the diagnosis.

Results: Out of 49 positive on PAP smear, 24 were true positives and 25 were false positives. Out of 51 negative PAP smear findings, 45 were true negatives and 6 were false negatives.

Thirty percent women had positive histopathology and colposcopic findings. Forty percent women had normal colposcopy with negative histopathology whereas $30 \%$ had positive colposcopic findings but negative histopathology. Nineteen percent of women with negative cytology were positive on colposcopy and histopathology.

Conclusion: PAP smear had a sensitivity of $80 \%$ and a specificity of $64.29 \%$ with positive predictive value of $48.98 \%$ and negative predictive value of $88.24 \%$ while sensitivity and specificity of colposcopy were 100 and $57.14 \%$ respectively and positive predictive value and negative predictive value of colposcopy were found to be 50 and $100 \%$ respectively.

Keywords: PAP smear, Colposcopy, Premalignant lesions of cervix.

How to cite this article: Kohli B, Arya SB, Goel JK, Sinha M, Kar J, Tapasvi I. Comparison of PAP Smear and Colposcopy in Detection of Premalignant Lesions of Cervix. J South Asian Feder Menopause Soc 2014;2(1):5-8.

Source of support: Nil

Conflict of interest: None

\section{INTRODUCTION}

The cervix is the commonest site for female genital cancer. According to Indian Council of Medical Research (ICMR), the incidence of cervical cancer in India varies from 20 to

\footnotetext{
${ }^{1}$ Junior Resident, ${ }^{2}$ Associate Professor, ${ }^{3}$ Professor and Head ${ }^{4,6}$ Assistant Professor, ${ }^{5}$ Professor

${ }^{1-6}$ Department of Obstetrics and Gynecology, Sri Ram Murti Smarak Institute of Medical Sciences, Bareilly, Uttar Pradesh, India

Corresponding Author: Bahar Kohli, Junior Resident, Department of Obstetrics and Gynecology, Flat no. F-225, Doctors Residence Sri Ram Murti Smarak Institute of Medical Sciences, Nainital Road, Bhojipura, Bareilly, Uttar Pradesh, India Phone: 0581-2582170, e-mail: baharkohli@gmail.com
}

35 per 100,000 women between the age group of 35 and 64 years while in developed countries it is as low as 1 to 8 per 100,000 women. In India, 132,000 new cases are reported annually with 74,000 deaths occurring each year hence, every 7 th minute a woman dies due to cervical cancer. ${ }^{1}$ It is predicted that figures are expected to double by 2020 if no action is taken. ${ }^{2}$

Despite the fact that more than $80 \%$ of cervical cancer cases are in developing countries, only $5 \%$ of women there have ever been screened for cervical abnormalities. ${ }^{3}$

The papanicolaou (PAP) smear is a simple, safe, noninvasive, and effective method for detection of precancerous, cancerous and noncancerous changes in the cervix and vagina. ${ }^{4}$

Implementation of centralized cervical cytology screening programs is not possible in the villages of India where $58 \%$ of females in rural areas are illiterate, health infrastructure is mediocre, and cervical cytology is unknown.

International agency of research on cancer (IARC) reported $93 \%$ reduction in the incidence of cervical cancer when women aged between 35 and 64 years were screened at 1 to 3 yearly, $84 \%$ reduction when screened 5 yearly and $64 \%$ reduction when screened 10 yearly.

In 1925 Hinsellmann first hypothesized visualization of cervical epithelium under magnification. Colposcopy provides a unique method to study the benign and premalignant lesions. The colposcope is a binocular microscope used for direct visualization of the cervix enabling a view of the transformation zone which is the junction between the squamous and columnar epithelium in evaluating abnormal PAP smear.

Various studies on colposcopy incurs only few false negatives giving a general accuracy rate of $98.3 \%$. Sensitivity of colposcopic examination is $83.6 \%$ and there is high accuracy in correlation between colposcopy and histology. ${ }^{5}$

Colposcopy is observer dependent gives faster results and guides the site of biopsy which can be done in a single visit making it probably a better screening modality for premalignant lesions in symptomatic patients.

Despite of introduction of PAP smear and colposcopy for many years still the mortality and morbidity with cervical cancer is 274,000 and 493,000 respectively each year in India. ${ }^{6}$ To best of our knowledge, no screening test is yet 
$100 \%$ specific. Thus, there is scope for evaluating existing modalities as well as research for newer modalities of screening cancer cervix. That is why present study was planned to evaluate the role of colposcopy in comparison to PAP smear in symptomatic patients in detecting premalignant lesions of cervix.

\section{AIM AND OBJECTIVES}

To compare the efficacy of PAP smear and colposcopy in detecting the premalignant lesions of cervix.

\section{MATERIALS AND METHODS}

This study was conducted in the department of obstetrics and gynecology at Shri Ram Murti Smarak Institute of Medical Sciences, Bhojipura, Bareilly from May 2012 to May 2013 after taking approval from institutional ethical committee. This was a prospective clinical study conducted in 100 sexually active women of age group 20 to 60 years with various symptoms such as abnormal vaginal discharge, backache, abdominal pain, irregular menstrual bleeding, postmenopausal bleeding and postcoital bleeding were examined and women with abnormal looking cervices were recruited. Women who were known cases of genital malignancy, premalignant lesions of cervix, pregnant women and who had undergone total hysterectomy were excluded from the study.

After taking informed consent and counseling of patients, detailed history, general examination and systemic examination was done. Informations were noted on pretested proforma. Per speculum examination was also done followed by pap smear and pervaginum examination. All the women were subjected to colposcopy and cervical biopsy.

Papanicolaou smear was done after evacuating the bladder in dorsal position. Bivalved Cusco's speculum introduced without any lubricant. Ectocervix scraped with

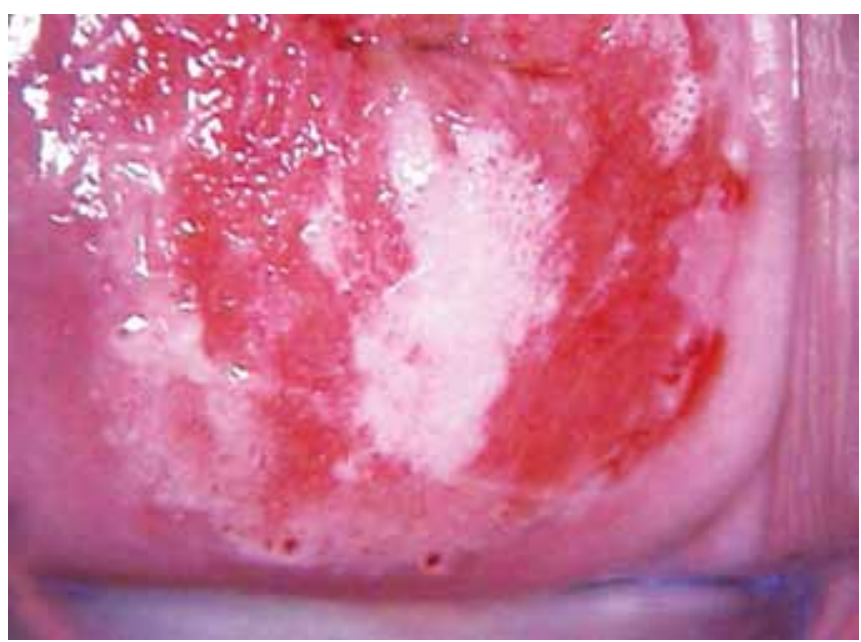

Fig. 1: Colposcopic image of CIN III lesion with acetowhite area with coarse punctuations the Ayre's Spatula by turning $360^{\circ}$, making sure to cover the entire transformation zone and endocervix with endocervical brush.

The cellular material thus obtained was quickly but gently smeared on two clean glass slides. The glass slides were then immediately put into a labelled Coplin jar using patient's name, registration number and consultant's name containing $95 \%$ ethyl alcohol, which acted as a fixative and submitted to the pathology department.

The prepared smears were then stained according to the conventional PAP technique. After staining the samples were examined by a pathologist under a light microscope. The cytological interpretation of the smears were made according to the Bethesda system 2001.

The colposcope used in this study was of Borze stereophoto-colposcope model no. DVC-6000 at magnification of $7.5 \times$ and $15 \times$. Patients were laid in dorsal position, cervix exposed with self-retaining Cusco's speculum colposcopic examination was done after cleaning with normal saline inspection was done firstly by green filter followed by $3 \%$ acetic acid and Lugol's iodine application (Figs 1 and 2).

Margin of lesion, color of lesion, appearance of blood vessels and iodine staining reaction noted and documented. Reid's score (Table 1) was used to predict the grading of abnormal colposcopic findings.

Punch biopsy was taken from the colposcopic suspicious areas of cervix or in normal looking cervices four quadrant biopsy was taken and sent for histopathological examination. Hematoxylin and eosin stain was used for staining.

Statistical analysis was carried out by Chi-square test for calculating sensitivity, specificity and positive and negative predictive value of PAP smear and colposcopy.

\section{RESULTS}

In our study, maximum number of women, i.e. $63 \%$ were in age group between 30 and 49 years whereas in age group

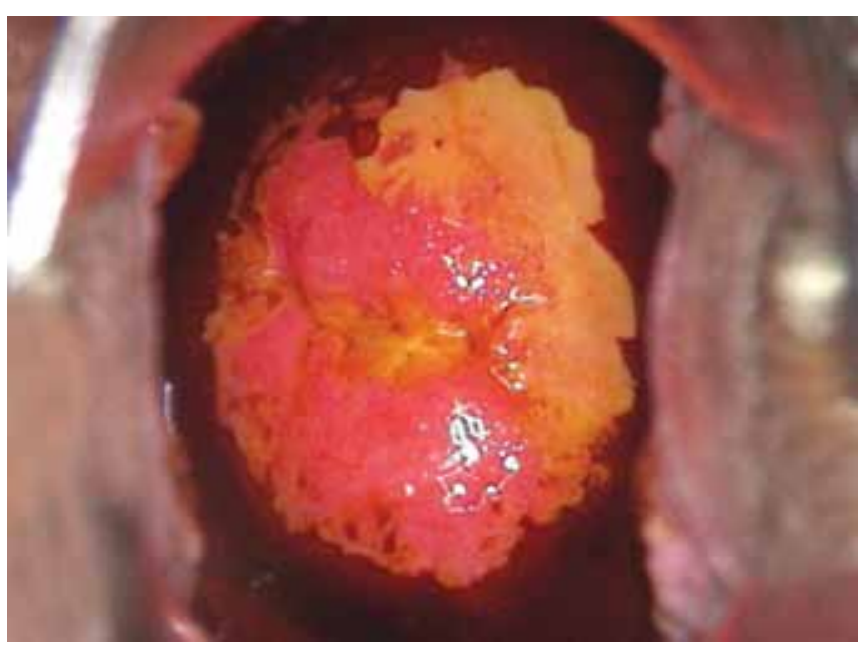

Fig. 2: Colposcopic image of CIN III lesion with negative iodine uptake 


\begin{tabular}{|c|c|c|c|}
\hline & Zero point & 1 point & 2 points \\
\hline 1. Margin & $\begin{array}{l}\text { Condylomatous } \\
\text { or micropapillary } \\
\text { contour } \\
\text { - Indistinct AW } \\
\text { - } \text { Feathered } \\
\text { margins } \\
\text { - Satellite } \\
\text { lesions and } \\
\text { AW that } \\
\text { extends } \\
\text { beyond TZ } \\
\text { - Angular } \\
\text { lesions }\end{array}$ & $\begin{array}{l}\text { Regular } \\
\text { lesions with } \\
\text { smooth } \\
\text { straight } \\
\text { outlines }\end{array}$ & $\begin{array}{l}\text { Rolled, } \\
\text { peeling edges } \\
\text { - Internal } \\
\text { demarcation } \\
\text { between } \\
\text { two areas } \\
\text { of differing } \\
\text { appearance }\end{array}$ \\
\hline 2. Color & $\begin{array}{l}\text { - Shiny, snow } \\
\text { white } \\
\text { - Indistinct AW }\end{array}$ & $\begin{array}{l}\text { Intermediate } \\
\text { grade (shiny } \\
\text { grey) }\end{array}$ & Dull, oyster white \\
\hline 3. Vessels & $\begin{array}{l}\text { Fine-caliber } \\
\text { vessels, poorly } \\
\text { formed pattern }\end{array}$ & $\begin{array}{l}\text { Absent } \\
\text { surface } \\
\text { vessels after } \\
\text { acetic acid } \\
\text { application }\end{array}$ & $\begin{array}{l}\text { Definite } \\
\text { punctuation or } \\
\text { mosaicism }\end{array}$ \\
\hline $\begin{array}{l}\text { 4. lodine } \\
\text { staining } \\
\text { reaction }\end{array}$ & $\begin{array}{l}\text { Positive iodine } \\
\text { staining } \\
\text { Minor iodine } \\
\text { negativity }\end{array}$ & $\begin{array}{l}\text { Partial iodine } \\
\text { negativity }\end{array}$ & $\begin{array}{l}\text { Negative } \\
\text { staining of } \\
\text { significant lesion }\end{array}$ \\
\hline $\begin{array}{l}0-2=\mathrm{HPV} \\
\text { or CIN I }\end{array}$ & $3-5=$ & $\mid-I I$ & $6-8=\mathrm{CIN}$ II-III \\
\hline
\end{tabular}

Table 2: Age-wise distribution of patients

\begin{tabular}{ll}
\hline Age $($ years) & No. of cases $(\%)$ \\
\hline $20-29$ years & $16(16)$ \\
$30-39$ years & $33(33)$ \\
$40-49$ years & $30(30)$ \\
$50-60$ years & $21(21)$ \\
\hline Total & 100 \\
\hline
\end{tabular}

Table 3: Parity-wise distribution of patients

\begin{tabular}{ll}
\hline Parity & No. of cases (\%) \\
\hline Nulliparous & $0(0)$ \\
1 to 2 & $23(23)$ \\
3 to 4 & $49(49)$ \\
$>5$ & $28(28)$ \\
\hline Total & 100 \\
\hline
\end{tabular}

Table 4: Correlation between histopathology and cytology

\begin{tabular}{lllll}
\hline & & \multicolumn{3}{c}{ Histopathology } \\
\cline { 3 - 5 } & & Positive & Negative & Total \\
\hline \multirow{2}{*}{ PAP smear } & Positive & 24 & 25 & 49 \\
& Negative & 6 & 45 & 51 \\
\hline \multirow{2}{*}{ Total } & & 30 & 70 & 100 \\
\hline
\end{tabular}

50 to 60 years there were $21 \%$ of the women. Mean age in the study was $39.91 \pm 9.64$ years (Table 2).

Maximum number of women studied, i.e. $49 \%$ were with parity 3 to 4 followed by $28 \%$ in $>5$, only $23 \%$ in parity 1 to 2 and there was no nulliparous women in our study (Table 3).
Table 5: Correlation between histopathology and colposcopy

\begin{tabular}{lllll}
\hline & \multicolumn{3}{c}{ Histopathology } \\
\cline { 3 - 5 } & & Positive & Negative & Total \\
\hline \multirow{2}{*}{ Colposcopy } & Positive & 30 & 30 & 60 \\
& Negative & 0 & 40 & 40 \\
\hline \multirow{2}{*}{ Total } & 30 & 70 & 100 \\
\hline
\end{tabular}

Table 6: Correlation between positivity of cytology with colposcopy and histopathology

\begin{tabular}{llll}
\hline \multirow{2}{*}{ Cytology } & \multicolumn{2}{c}{$\begin{array}{c}\text { Colposcopy and } \\
\text { histopathology }\end{array}$} \\
\cline { 3 - 4 } & & Positive & Negative \\
\cline { 2 - 4 } & Negative & 11 & 16 \\
& 19 & 28 \\
\hline
\end{tabular}

Among 100 women studied smear was normal in $7 \%$ of women, inflammatory in $44 \%$ women, whereas ASCUS was seen in $19 \%$ of the women followed by LSIL and HSIL in 13 and $11 \%$ women respectively. Squamous cell carcinoma was present in only $2 \%$ of the women.

Out of 49 positive PAP smear findings, 24 were true positives and 25 were false positives whereas out of 51 negative PAP smear findings, 45 were true negatives and 6 were false negatives (Table 4).

Papanicolaou smear had a sensitivity of $80 \%$ and a specificity of $64.29 \%$ with positive predictive value of $48.98 \%$ and negative predictive value of $88.24 \%$.

On colposcopy $40 \%$ of the women had normal colposcopic findings, followed by CIN 1 in $24 \%$, CIN $1-2$ in 28 and $8 \%$ of women had CIN 2-3.

In our study there were 30 women who had positive histopathology and colposcopic findings. Forty percent women had normal colposcopy with negative histopathological findings whereas $30 \%$ had positive colposcopic findings but their histopathology was negative (Table 5).

Sensitivity and specificity of colposcopy were 100 and $57.14 \%$ respectively with positive and negative predictive value 50 and $100 \%$ respectively.

Of all 100 cases subjected to biopsy, majority (68\%) had chronic cervicitis followed by $18 \%$ who had CIN 1 and $5 \%$ had CIN 2 . Only $2 \%$ of women had CIN $3 /$ CIS whereas squamous cell carcinoma was seen in 5\% cases.

Among 19 women who had negative cytology had positive colposcopy and histopathological findings whereas 16 women with positive cytology had negative colposcopy and histopathological findings (Table 6).

\section{DISCUSSION}

Because of accessibility of cervix, long preinvasive state, effective screening and treatment of preinvasive state, invasive cancer of cervix is considered a preventable disease. ${ }^{8}$ 
Sensitivity of PAP smear of our study was marginally less than in studies by Al Alwan et al 2001 (88.9\%), ${ }^{9}$ Maria et al $2009(91.7 \%)^{10}$ but it was way higher than Mojgan et al $2011(15 \%) .^{11}$

In our study specificity of PAP smear was almost $2 / 3$ rd of specificity in other studies by Al Alwan et al $2001(98.4 \%){ }^{9}$ Randomir et al 2005 (88\%), ${ }^{12}$ and Mojgan et al $2011(93 \%)^{11}$ and it was almost double than only one study by Maria et al $2009(34.6 \%){ }^{10}$

The sensitivity of PAP smear in our study was more than most of the studies as we recruited symptomatic patients with abnormal cervices which makes it a good screening method to detect lesions of cervix.

Sensitivity of colposcopy in our study was found comparable to many studies conducted by Olaniyan B 2002 $(87-99 \%),{ }^{13}$ Randomir et al $2005(96 \%)^{12}$ and Maria et al $2009(94.4 \%){ }^{10}$

Specificity of colposcopy in our study was consistent with many studies conducted by Olaniyan B $2002^{13}$ (26-87\%), Randomir et al $2005^{12}(57 \%)$, Maria et al $2009^{10}$ (50\%) and Ramesh et al $2012^{14}(46.42 \%)$.

There is high sensitivity but low specificity of colposcopy when compared to PAP smear. This may be due to the high incidence of unsuspected acetowhite epithelium which might be due to inflammation, immature metaplasia and latent human papilloma virus infections. ${ }^{15}$ The limitation of colposcopy is its dependence on observer variability and relatively weaker performance in differentiating normal cervix from low grade lesions. ${ }^{13}$

\section{CONCLUSION}

Our study concludes that colposcopy and guided biopsy seem better option than PAP smear for early diagnosis of preinvasive lesion in symptomatic women. So use of 'single visit approach' in which cytology, colposcopy and guided biopsy all are done in one sitting and treated accordingly in resource poor countries like ours will enable maximal utilization of scarce medical resources.

More research on larger cohort is needed to fully characterize use of colposcopy in symptomatic rural women.

\section{REFERENCES}

1. Parkin FJ, Pisani P. GLOBOLAN 2002: Cancer incidence, mortality and prevalence worldwide version IARC Cancer Base No. 5, Lyon: IARC Press, 2005.

2. Duraisamy K, Jaganathan KS, Bose JC. Methods of detecting cervical cancer. Advan Biol Res 2011;5(4):226-232.

3. World Health Organisation. Comprehensive cervical cancer control: a guide to essential practice. Geneva, WHO, 2006.

4. Khan MA, Raja FY, Ishfaq G, Tahir F, Subhan F, Kazi BM, et al. PAP smear screening for precancerous conditions of the cervical cancer. J Med Res 2005;44:111-113.

5. Boicea A, Pătraşcu A, Şurlin V, Iliescu D, Schenker M, Chiuţu L. Correlations between colposcopy and histologic results from colposcopically directed biopsy in cervical precancerous lesions. Rom J Morphol Embryol 2012;53(3 Suppl):735-741.

6. Ferlay J, Parkin DM, Pisani P. GLOBOLAN 2002: Cancer incidence, mortality and prevalence world wide version 1.0 IARC Cancer Base No. 5, Lyon: IARC Press, 2005.

7. Solomon D, Davey D, Kurman R, et al. The 2001 Bethesda System: terminology for reporting results of cervical cytology. JAMA 2002;287(16):2114-2119.

8. IARC. World Cancer Report 2008 IARC 2008.

9. Alwan A. Colposcopy, cervical cytology and human papillomavirus detection as screening tools for cervical cancer. Eastern Mediterranean Health Journal 2001;7:100-105.

10. Adamopoulou M, Kalkani E, Charvalos E, Avgoustidis D, Haidopoulos D, Yapijakis C. Comparison of cytology, colposcopy, HPV typing and biomarker analysis in cervical neoplasia. Anticancer Research 2009;29:3401-3410.

11. Zarchi MK, Binesh F, Kazemi Z, Teimoori S, Soltani HR, Chiti Z. Value of colposcopy in the early diagnosis of cervical cancer in patients with abnormal PAP smears at Shahid Sadoughi Hospital, Yazd. Asian Pacific J Cancer Prev 2011;12:3439-3441.

12. Živadinović R, Radović M, Lilić V, Petrić S. Grading the severity of preinvasive changes of the uterine cervix by colposcopy and exfoliating cytology. Facta Universitatis Series: Medicine and Biology 2005;12(1):55-59.

13. Olaniyan OB. Validity of colposcopy in the diagnosis of early cervical neoplasia a review. African J Reproductive Health 2002;6:59-69.

14. Ramesh G, Sudha R, Jayashree AK, Padmini J. Colposcopic evaluation of unhealthy cervix. JCDR 2012;4349:2271.

15. Gopal M, Joshi PS, Pukale R, Shamashoor. Colposcopic findings in Unhealthy cervix and its comparison with cytology and histopathology. J Evolution Med Dent Sci 2013;2(26): 4663-4671. 